\title{
Coping with wild boar in a conservation area: impacts of a 10-year management control program in north-eastern Argentina
}

\author{
Ricardo E. Gürtler • V. Martín Izquierdo • Guillermo Gil • \\ Marcelo Cavicchia $\cdot$ Aristóbulo Maranta
}

Received: 20 April 2016/Accepted: 9 August 2016/Published online: 21 October 2016

(C) Springer International Publishing Switzerland 2016

\begin{abstract}
Wild boar (Sus scrofa) are of serious concern in numerous conservation areas such as El Palmar National Park, Argentina, where their increasing abundance affected the iconic palm tree Butia yatay. We assessed the effectiveness of an innovative management control program on wild boar population dynamics and ground rooting area over 10 years. Park personnel recruited and supervised local recreational
\end{abstract}

R. E. Gürtler $(\bowtie)$

Laboratory of Eco-Epidemiology, Department of

Ecology, Genetics and Evolution, Universidad de Buenos

Aires-IEGEBA (CONICET-UBA), Ciudad Universitaria,

1428 Buenos Aires, Argentina

e-mail: gurtler@ege.fcen.uba.ar

V. Martín Izquierdo

Parque Nacional Los Alerces, Administración de Parques

Nacionales, Primeros Pobladores S/N,

9200 Villa Futalaufquen, Chubut, Argentina

G. Gil · M. Cavicchia

Delegación Regional del Noreste Argentino,

Administración de Parques Nacionales, Av. Tres

Fronteras 183, 3370 Puerto Iguazú, Misiones, Argentina

\section{A. Maranta}

Parque Nacional El Palmar, Administración de Parques

Nacionales, Ruta Nac. 14, km 19, 3287 Ubajay,

Entre Ríos, Argentina hunters who regularly conducted controlled still shooting from widely distributed watchtowers and used trained dogs mainly during the first 2 years postintervention (YPI). We used the detailed records of harvest and hunting effort to estimate time- and stagespecific catch-per-unit-effort (CPUE) indices and stochastic population growth rates $(\mu)$. Catch was linearly related to hunting effort except at large effort levels. CPUE indices declined exponentially at 5-7\% month ${ }^{-1}$ over $0-1$ YPI and thereafter stabilized with $\mu$ indistinguishable from 0 . Relative to baseline levels, culling reduced annual pregnancy rates, the fraction of juveniles and older adults, and ground rooting area below target values $(<1.3 \%)$. Incipient population recovery followed one of two periods of marginal hunting effort. The program generated few undesirable collateral effects mainly related to dog-hunting. Mesopredator abundance (foxes) steadily increased following a large outbreak of canine distemper at baseline. The combined use of standardized CPUE indices, body-length data and simple population viability analysis models provided reliable metrics for wild boar trend analysis and management. Unlike a preceding plan, a highly structured multi-stakeholder program proved to be sustainable and brought wild boar abundance to a low-density, unstable equilibrium causing minimal damage.

Keywords Conservation areas - Sustainability . Wild boar · Population dynamics - Wildlife management $\cdot$ Ungulates 


\section{Introduction}

The wild boar Sus scrofa (Linnaeus 1758) features a prominent role among the top invasive species (Lowe et al. 2004), with a wide distribution over five continents and many oceanic islands (Barrios-García and Ballari 2012). Wild boar populations are expanding in range and numbers worldwide as a result of illegal introductions for bush meat and sport or commercial hunting, expansion and intensification of agricultural crops, land abandonment, reforestation, global warming, and hunting restrictions leading to inadequate harvest policies (Gamelon et al. 2012; Massei et al. 2015; Vetter et al. 2015). Conflicting views on wild boar as both a desired game animal and an undesired pest coexist in some areas (Choquenot et al. 1996).

The wild boar is a broad-niche, omnivorous species with most of the attributes of a successful invader and of a 'fast' mammal that can rapidly adjust onset of reproduction and female fertility to changing habitat quality (Oli and Dobson 2003; Bieber and Ruf 2005). Wild boar reach large asymptotic population growth rates $(\lambda)$ and densities (Bieber and Ruf 2005; Gamelon et al. 2012), and adapt easily to multiple habitats including peri-urban settings. They exert large impacts on vegetation community structure and dynamics through rooting of the soil, nest building and trampling, predation on small vertebrate and invertebrate fauna, competition with native species, crop raiding, transmission of several pathogens affecting human and animal health, and hybridization with domestic pigs (Choquenot et al. 1996; Hone 2002; Campbell and Long 2009; Barrios-García and Ballari 2012). Such impacts warranted launching eradication or control programs in island and continental settings (Hone 2002; Cruz et al. 2005; Parkes et al. 2010). Control methods include walk-in baited traps and snares; ground, vehicle and aerial shooting with firearms; hunting with trained dogs; bait poisoning, and the Judas' pig technique (West et al. 2009; Campbell and Long 2009; Massei et al. 2011). Wild boar management programs in conservation areas are frequently challenged by multiple constraints, and their sustainability (i.e., the ability to maintain a set of formal organized activities and its benefits over time) has received little attention.

Wild boar occur in $21 \%$ of the 76 conservation areas across Argentina (Merino et al. 2009) following the deliberate introduction of Euroasian specimens to northern Patagonia around 1904-1917 (Novillo and Ojeda 2008; Barrios-García and Ballari 2012). Their increasing abundance is of serious concern in several protected areas (Novillo and Ojeda 2008; Simberloff et al. 2003; Pérez Carusi et al. 2009). The first occurrence of wild boar in El Palmar National Park (hereafter El Palmar or the park) dates back to 1976 (Crespo 1982) whereas the initial (opportunistic) control efforts of wild boar and exotic deer were in 1983. Preliminary data showed that wild boar consumed large numbers of seeds and saplings of the iconic yatay palm tree (Butia yatay), eggs of groundnesting birds, offspring of native deer, and upturned substantial portions of soil (Goveto 1999). Therefore, as part of a control plan initiated in 1995-1996, park rangers culled exotic ungulates using trained dogs and shooting from vehicles and watchtowers. In practice, hunting efforts were conducted non-systematically, and lack of sufficient resources devoted to the plan allowed wild boar abundance to continue increasing. Cage experiments allowing the selective exclusion of foragers in a 3.4 ha plot demonstrated that wild boar were the main cause of yatay palm seedling mortality from mid-2006 to late 2007 (Pignataro 2010). Moreover, a detailed longitudinal survey showed that wild boar in El Palmar mainly consumed fruits, seeds and saplings of the yatay palm tree and from invasive exotic plants during the fruiting season, other plant matter (including corn used as bait for wild boar hunting) and bird remains (Ballari et al. 2015).

In light of this evidence, a new multi-stakeholder management program targeting wild boar, axis deer and black bucks Antilope cervicapra (rarely sighted after 1990s) was implemented since 2006. Here we assess its impacts on wild boar population dynamics and ground rooting area over a 10-year period by using detailed records of harvest and hunting effort to estimate period- and stage-specific catch-per-uniteffort (CPUE) indices and stochastic population growth rates. "Long-term monitoring of hunted [ungulate] populations is mostly lacking" (Servanty et al. 2011), partly because of lack of guidance on costeffective monitoring techniques and lack of detailed information on culling effort. We address this gap by careful standardization of CPUE indices, after verifying that catch (i.e., harvest size) and hunting effort per quarterly period were linearly related over most of the broad range of effort. CPUE indices, classically used 
for stock assessment of fish and a few game populations, may be quite misleading when certain assumptions are not met (Clark 1985; Hilborn and Walters 1992; Lancia et al. 1996; Skalski et al. 2005). We show that a highly structured management program reduced wild boar abundance to a low-density, unstable equilibrium causing minimal damage. The impacts on axis deer will be reported separately. We also discuss the relative success and long-term sustainability of wild boar control efforts, with the intent of developing improved management strategies of exotic ungulates in conservation areas.

\section{Materials and methods}

Study area

El Palmar National Park, located at $31^{\circ} 55^{\prime} \mathrm{S}, 58^{\circ} 16^{\prime} \mathrm{W}$ in Entre Ríos Province (Argentina), was created in 1965 to preserve one of the few extant high-density stands of the yatay palm (Fig. 1). The park covers approximately 8500 ha of undulating terrain including savannas, grasslands, scrublands and gallery forests (Batista et al. 2014), embedded in a landscape of eucalyptus and pine plantations, cattle ranches, and soybean or wheat crops. Several summer wildfires have burned large tracts of the park approximately once every decade since 1970 . The nearest town (Ubajay, 3000 residents) is $12 \mathrm{~km}$ far from the park, which annually receives $>100,000$ visitors. Mean temperatures at the nearest weather station (Concordia) over 2005-2014 were $19{ }^{\circ} \mathrm{C}$ (minimum and maximum, 1.5 and $33.4{ }^{\circ} \mathrm{C}$ ); frosts occurred between May and October and annual mean rainfall was $1384 \mathrm{~mm}$.

\section{Program design}

Conceived within an adaptive management framework, the main objectives of the 2005 control program were to: "(i) reduce the ground rooting area to less

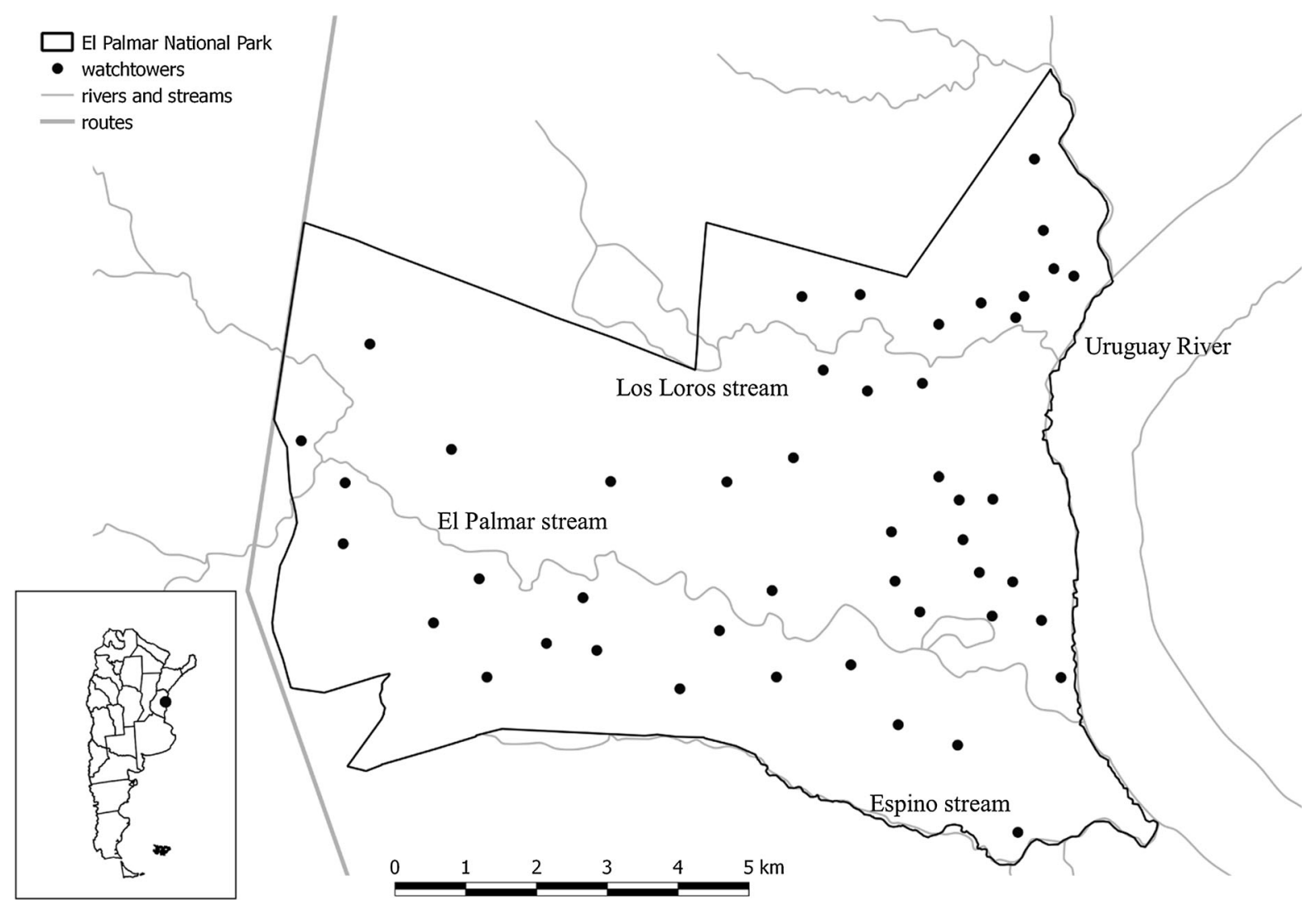

Fig. 1 Map of El Palmar National Park showing the location of watchtowers and water courses in Entre Rios province, north-eastern Argentina 
than a third of the existing one at the beginning of the plan and to maintain or reduce the amount over time, and (ii) reduce the negative impacts of wild boar on the recruitment of yatay palms and maintain this trend over time".

The essence of the program was to recruit local sport and subsistence hunters (a long-standing local tradition) who would operate under a regulated framework compatible with park conservation goals, contribute resources unavailable to the park, minimize poaching, and expand the number of local stakeholders interested in the control program. For the first time ever in Argentina the management program allowed authorized third parties to conduct controlled hunting within park premises. Park rangers initially met with the local hunting club to explain the new policy and invite hunters to join the program. No harvest quotas were set. Hunters signed a contract binding them to conduct non-selective hunting and comply with safety measures and other regulations. Only one annual trophy was allowed to each hunter; specimens' heads were retained to prevent selective hunting.

Hunting methods

After a pilot trial of several methods, three techniques were implemented: controlled still shooting, hunting with dogs, and shooting from vehicles. For vehicle hunting, park personnel drove pick-up trucks along the existing roads and trails, used spotlights to locate the boars, and shot them from the open back.

For controlled still shooting, hunters built 4-6 m high watchtowers in designated sites accessible through existing or new trails across the park and $500 \mathrm{~m}$ from the nearest watchtower (Fig. 1); the total number of watchtowers increased from 35 (2006) to 44 (2015). Hunters were required to have a license and their firearms registered, contract a life insurance policy, keep the watchtower in safe conditions, and bait their surroundings with corn, ground pet food or salt on two designated days before hunting sessions. Firearm calibers and shooting conditions (including restricted shooting angles adapted to the context of each watchtower) were stipulated by the park to prevent risks to third parties and minimize animal suffering. Each watchtower was required to house a minimum of two and up to three participants, including authorized shooters and companions. Hunters carried VHF radios to communicate with the park ranger supervising the hunting session at a central operating post and to request permission to shoot when they were sure of a clean kill or to put down a wounded animal; they were not allowed to chase specimens. Hunting sessions were conducted every 2-4 weeks, generally starting at $1800 \mathrm{~h}$ and frequently extending past midnight over 2006-2007. The duration of hunting sessions depended on park stipulations, weather conditions, and individual hunter's choices. Park visitors had restricted mobility during hunting sessions. An average hunting session employed five park staff members who contributed half as much work time as external hunters to direct hunting efforts during 2006-2007.

Hunting with trained dogs was mainly conducted by external hunters who used their dogs, and less frequently by park staff using park dogs or external hunters using park dogs. Pack size averaged 8-9 dogs (generally of mixed breed) kept under veterinary supervision and vaccinated against canine pathogens. All hunting parties were headed by park personnel and used horses, and most started before $900 \mathrm{~h}$. Trained dogs found and bailed the pig until the hunter came and dispatched it with a knife, or rarely with a firearm used by the park ranger. Dogs that molested wildlife on more than two occasions were separated from the pack.

For each hunting party (i.e., group of hunters sharing a watchtower, vehicle or a dog pack) and occasion, park staff filled up a form regardless of whether any wild boar or deer was dispatched or the session was unsuccessful. The form included the date, hunters' names, type of hunt, initiation and termination times of the hunting session, firearms and calibers, catch time, number and source of dogs, each specimen's morphometric measurements (see below), whether any boar was wounded and escaped, any undesirable event involving non-target species, and incidental observations.

Measurement and handling of specimens

Upon completion of each session, hunters brought the specimens to the central operating post where they were classified by stage and sex, measured (body length, height at withers, thorax diameter, tail length, ear length and length of metatarsus), butchered, and identified with a precinct. We assigned the specimens qualitatively to four stages using established relations 
between body length and age (Moretti 1995): juveniles were up to $99 \mathrm{~cm}$ (approximately 4-8 months of age, with a reddish fur coat); young adults measured between 100 and $120 \mathrm{~cm}$ (8-12 months old); mature adults, 121-135 cm (13-18 months old), and older adults, $136 \mathrm{~cm}$ or more (greater than 19 months old). The very few squeakers ( $\leq 4$ months old) culled were included among juveniles.

Pregnancy status and the number of embryos were systematically recorded from 2006 to 2009. A fragment of mandible muscles was removed, labeled and shipped to assess infection with the prevalent nematode Trichinella spiralis (Cohen et al. 2010). The piece was preserved at $-20^{\circ} \mathrm{C}$ and released within a week if safe for consumption. Hunters were allowed to take home $50 \%$ of each piece (67\% since 2012); the remainder was donated to local public schools, community shelters, retirement homes, and park personnel.

Pig rooting and fox abundance

Nine fixed strip transects (measuring $12 \mathrm{~m}$ by $1000 \mathrm{~m}$ ) were designated in palm tree stands scattered through the park; georeferenced with a GPS (Garmin), and inspected for pig rooting in September 2006, April 2007, September-December 2007, July 2008, July and September 2011, August 2012 and 2013, January and September 2014. The area inspected totaled $80,280 \mathrm{~m}^{2}$ in 2006, 48,000 $\mathrm{m}^{2}$ in January 2014 and $108,000 \mathrm{~m}^{2}$ in each of the other surveys. Two people riding horses separated by $>6 \mathrm{~m}$ inspected $3 \mathrm{~m}$-wide strips on each side and measured the width and length of the soil removed or covered attributable to wild boar (i.e., based on its general aspect and whether the excavations were continuous, shallow, with soil pushed forward, eventually containing boar tracks). Only new pig rootings (i.e., lacking any emerging seedling) were taken into consideration during follow-up surveys.

Monitoring of fox abundance was conducted on the same dates as rooting surveys (except in January 2014) to monitor program effects on other wildlife. Two people riding on the back of a vehicle circulating at $10 \mathrm{~km} / \mathrm{h}$ along all park roads and trails used spotlights to sight crab-eating foxes (Cerdocyon thous) and red foxes (Dusicyon gymnocercus) at dawn. Sightings were repeated on two consecutive days per survey (total distance, 111-124 km) and averaged.
Data management and analysis

The data from each hunting form were entered in an Excel database. For 158 specimens with complete morphometric measurements (excluding tail length) which lacked species identification, we conducted a discriminant analysis of $\log _{10}$-transformed morphometric measurements (excluding tail length) to assign them to wild boar or deer using the CLIC package (available at www.mpl.ird.fr/morphometrics). The database with complete morphometric measurements of identified wild boar (1666) and axis deer (1631) was used to create the reference groups (Gaspe et al. 2013). Cross-checked reclassifications showed that $91 \%$ of boars and $90 \%$ of deer were correctly assigned to the reference group. Fifty-five specimens with unknown species identity were assigned to wild boar. Missing data for sex, body length and time of catch were assumed to occur at random.

We assessed variations in the relative abundance of the standing wild boar population by means of period-specific CPUE indices (i.e., number killed per 100 party-hours). The CPUE index ( $C / E$, aggregate catch per aggregate effort) is linearly related to density $D$ (abundance relative to area, N/A) through the catchability coefficient $q$, under the assumptions of equal $D$ across the area, units of effort (parties) acting independently, catch probabilities low, and $q$ and $A$ constant (Clark 1985; Hilborn and Walters 1992; Skalski et al. 2005). Aggregate catch $C$ was taken as the sum of all wild boar dispatched in a given hunting session (i.e., date) by a defined method: $C_{. t}=\Sigma C_{j, t}$, where $j$ is an identified hunting party at time period $t$ (session, quarter and year), and .t stands for summation over $t$. $C$ includes a few specimens shot and discarded, and here is considered synonymous to harvest. Aggregate hunting effort $E_{\text {.t }}$ was measured as the total number of party-hours over $t$ for each hunting method. For a given session from watchtowers, $E_{. t}$ was computed as the total duration of the session $\left(\pi_{j, t}\right.$, the difference between termination and initiation times of each hunting party) summed over all hunting parties $j$ at time $t$. This calculation assumes that two hunters with firearms in a defined watchtower $j$ at time $t$ would operate in a perfectly dependent manner; i.e., usually the one who first spotted the animal shot the target. On few occasions were two or more wild boar dispatched at the same spot and time. 
To assess the impact of management actions over time, we used a count-based, density-independent population viability analysis (PVA) model to estimate the mean $(\mu)$ and variance $\left(\sigma^{2}\right)$ of the stochastic population growth rate of wild boar over a higherintensity (2006-2007) and lower-intensity (2008-2015) intervention period. We conducted a linear regression forced through the origin of the ratio between $\log _{\mathrm{e}^{-}}$ transformed CPUE indices on successive quarters postintervention (January-March, taken as the first quarter, summer), and then tested whether $\mu$ was significantly different from 0 (Morris and Doak 2002). All catches were increased by one unit. For still shooting we computed standardized CPUE indices by restricting hunting efforts and catches to the 1700-2300 h period to allow for increased catches over this period and the much longer duration of sessions during the first (baseline, 2006) and second years post-intervention (YPI, 0-1). All procedures were run in Stata 12 (StataCorp 2011). Stage- and year-specific variations in sex ratios (i.e., proportion of males over all wild boar staged and sexed) and pregnancy rates (i.e., proportion of pregnant adult females culled between June and September, taken as the reproductive season, over 0-3 YPI) were analyzed with multiple logistic regression. Sparse information did not allow testing for similar effects on female fecundity.

\section{Results}

Aggregate catch and hunting effort

A total of 1999 wild boar was dispatched over 591 sessions involving 5693 hunting parties (Fig. 2a). Most catches were accomplished by still shooting (80.6\%), followed by dog-hunting (18.3\%), and very few were from vehicles (1.1\%) (Fig. 2a). Most $(80.7 \%)$ of the 161 timed catches from watchtowers conducted overnight at baseline occurred between 1700 and $2300 \mathrm{~h}$, and were not significantly related to sex regardless of hunting methods (Mann-Whitney test, $P=0.25$ ). Relative to all wild boar dispatched by still shooting (197) during 2015, $4.6 \%$ reportedly escaped wounded.

The components of hunting effort varied strongly over time and methods (Fig. 2b,c). The per quarter frequency of still-shooting parties increased across the period, especially from late 7 YPI on, whereas hunting sessions were more variable and registered little or no activity over 6-7 YPI. The average duration of stillshooting sessions sharply decreased from 11.9 to $14.7 \mathrm{~h}$ to roughly $5 \mathrm{~h}$ from 2 YPI on (Fig. 2d), whereas dog-hunting sessions averaged $4.9 \mathrm{~h}$ and were mostly ( $88 \%$ ) contributed by external hunters.

Aggregate catch and hunting effort were linearly related both for still shooting (slope coefficient $b=0.04957$, standard error of $b, \mathrm{SE}(b): 0.00312$, $P<0.001$, Adj. $\left.R^{2}=0.875, \mathrm{n}=36\right)$ and dog-hunting $(b=0.27209, \quad \mathrm{SE}(b): 0.01746, \quad P<0.001, \quad$ Adj. $R^{2}=0.931, \mathrm{n}=18$ ) (Fig. 3). Catches were more variable at large still-shooting efforts. Addition of a squared term for effort was statistically significant only for still shooting $(b=0.08185, \mathrm{SE}(b)$ : 0.01006; $b_{1}=-0.000028, \quad \mathrm{SE}\left(b_{1}\right): \quad 8.36 \quad \mathrm{e}-06, \quad$ Adj. $\left.R^{2}=0.903\right)$. Another measure of effort, the total number of hunting parties per quarter, was also closely related to catch by still shooting $(b=0.27367, \mathrm{SE}(b)$ : $0.02125, P<0.001$, Adj. $\left.R^{2}=0.821\right)$.

CPUE and population growth rates

The standardized CPUE of wild boar by both methods steeply declined to a minimum on early 2 YPI (Fig. 4), when the stochastic population growth rate $(\mu)$ of wild boar was -0.04962 month $^{-1} \quad(\mathrm{SE}(b)$ : 0.06153 ; $\left.\sigma^{2}=0.61834\right)$ for still shooting, and -0.07827 $\left(\mathrm{SE}(b): 0.09342 ; \quad \sigma^{2}=0.10225\right)$ for dog-hunting. CPUE indices for both methods were significantly correlated $(r=0.771, d f 7, P=0.015)$. For still shooting from early 2 YPI on, $\mu$ averaged 0.00353 month $^{-1}$ (SE $\left.(b): 0.02614 ; \sigma^{2}=0.06153\right)$, thus indicating population stability with very wide fluctuations. Incipient recovery of wild boar numbers over 5-6 YPI (Fig. 4) matched the concomitant decrease in hunting effort whereas the low value by early-6 YPI was based on only one session (Fig. 2b, c).

Stage structure

The stage structure of wild boar culled by still shooting significantly differed among years $\left(\chi^{2}=78.73, d f 27\right.$, $P<0.001)$, with a clear decline in the fraction of older adults and juveniles over 1-2 YPI relative to baseline values and an upsurge of juveniles on early-5 YPI (Fig. 5). Harvests achieved by still shooting and doghunting displayed significantly different stage distributions $\left(\chi^{2}=46.19\right.$, df $\left.3, P<0.001\right)$. Most of the 
a

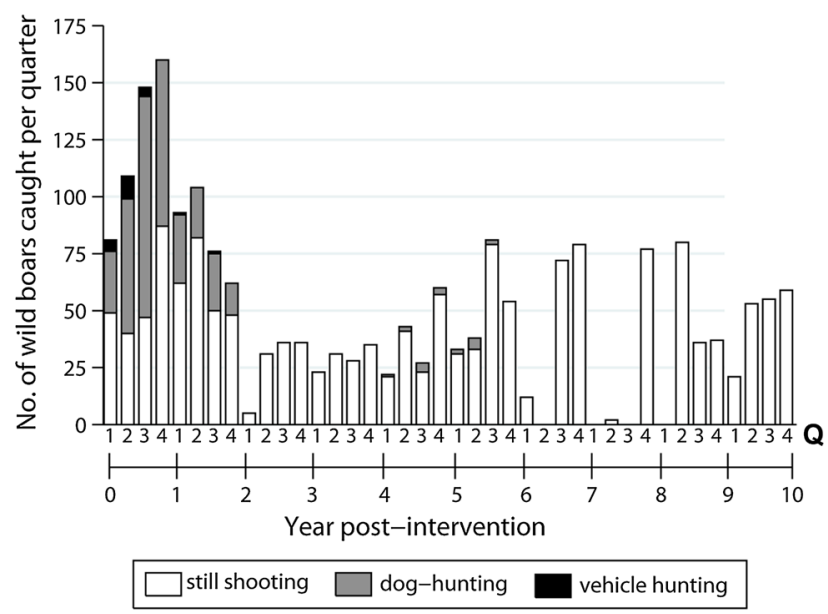

\section{c}

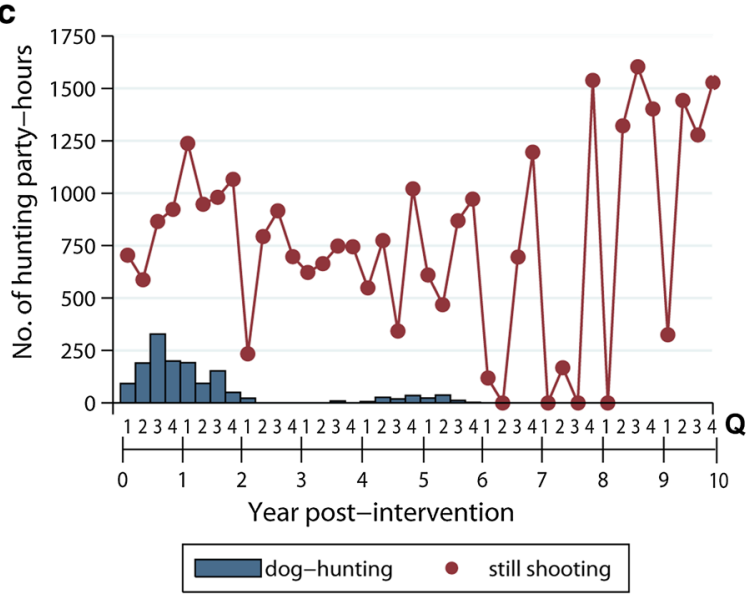

b

$\mathbf{Q}=$ Quarter

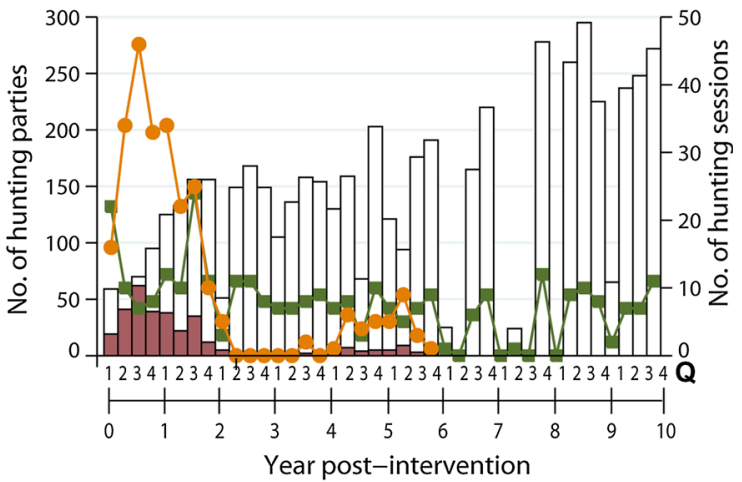

$\square$ still hunting parties $\square$ dog parties

$\longrightarrow$ - still sessions $\longrightarrow-$ dog-hunting sessions

d

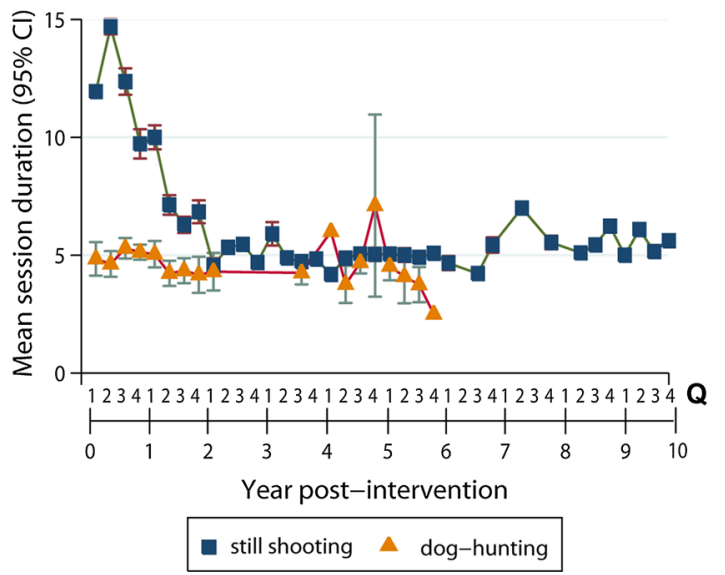

Fig. 2 Catch of wild boar (a), frequency of hunting sessions and parties (b), aggregate effort (c) and duration of sessions (d) according to hunting method and quarterly period in El Palmar, 2006-2015

Fig. 3 Linear regression of aggregate catch of wild boar on aggregate hunting effort using still shooting (a) and trained dogs (b) over quarterly periods in $\mathrm{El}$ Palmar, 2006-2015
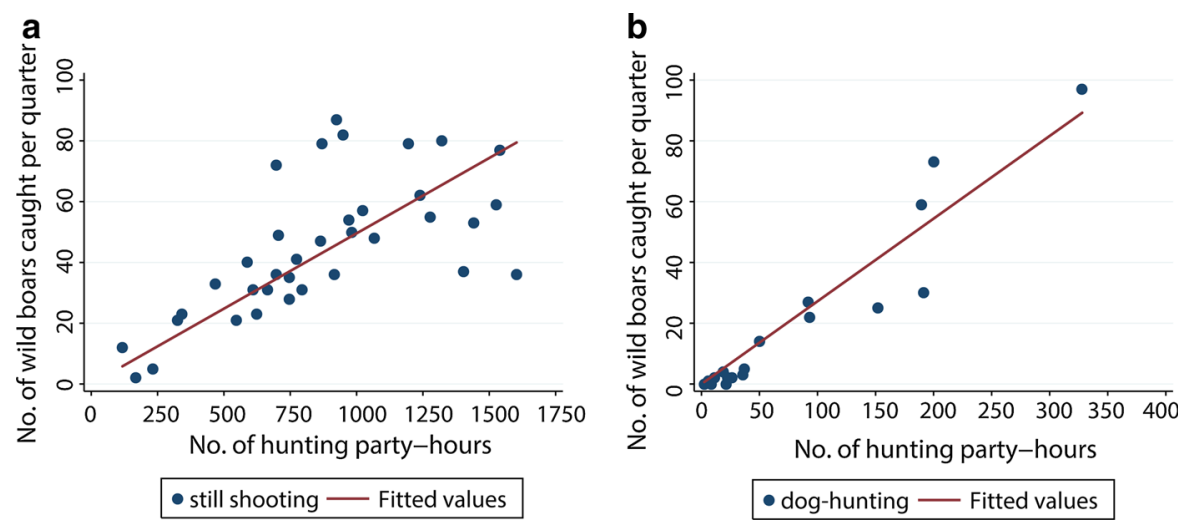

specimens shot were older (31.6\%), mature $(28.5 \%)$ and young adults $(25.6 \%)$, with only one squeaker being shot, whereas the stage distribution via dog- hunting displayed a higher frequency of juveniles than still shooting. Taken across methods, juveniles were most frequent over spring $(32.0 \%)$ and summer 


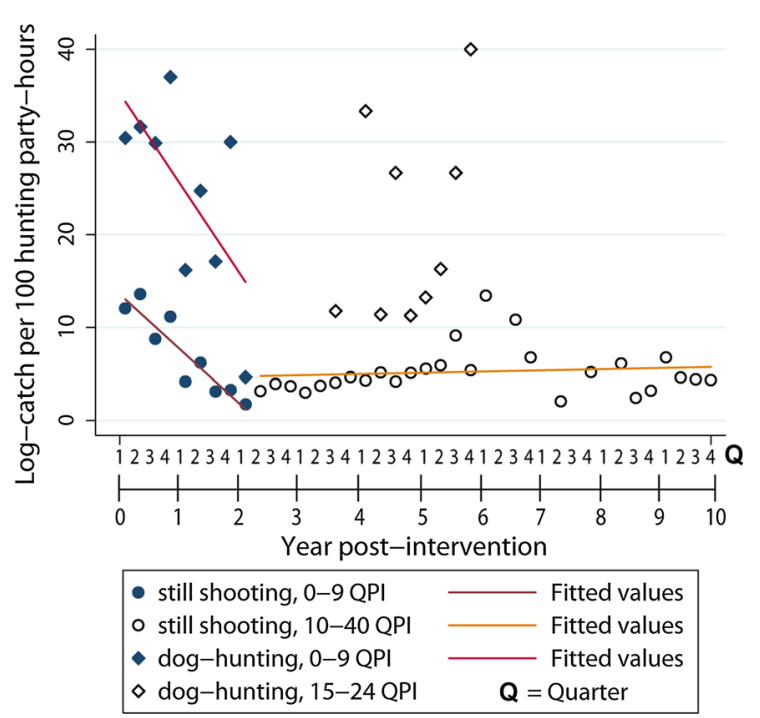

Fig. 4 Log-transformed standardized catch-per-unit-effort (CPUE) indices of wild boar culled by still shooting (standardized CPUE) and dog-hunting in El Palmar, 2006-2015

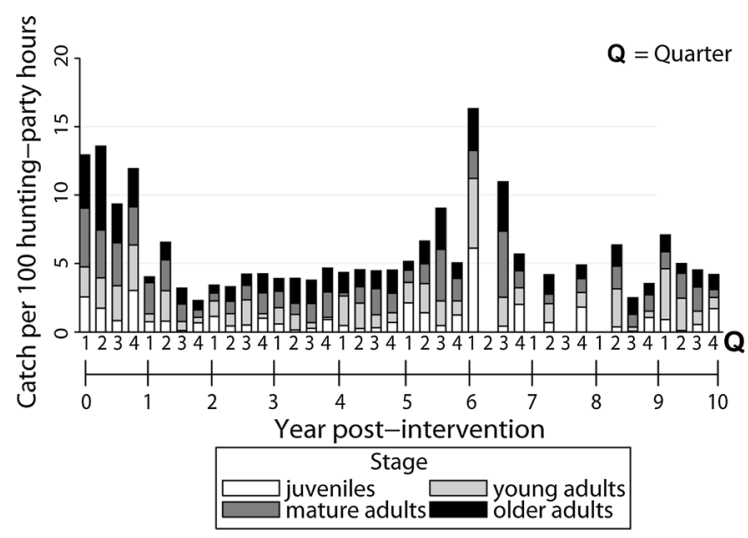

Fig. 5 Stage distribution of wild boar as determined from standardized catch-per-unit-effort indices estimated by still shooting in El Palmar, 2006-2015

$(30.2 \%)$ and then steadily decreased to a minimum in winter $(8.0 \%)$ when mature $(35.6 \%)$ and older adults $(34.4 \%)$ peaked. Enhanced recruitment of young adults in autumn and mature adults in winter followed the spring-summer peak of juveniles.

The percentage of males averaged $54.1 \%(95 \%$ confidence interval, 51.7-56.5\%) among 1,629 wild boar classified by sex. Overall sex ratios differed marginally between still shooting and dog-hunting $\left(\chi^{2}=3.61\right.$, df $1, P=0.057$ ), with a consistent bias toward males across stages shot (range 52.2-55.8 \%) and more variable stage-specific sex ratios by dog- hunting (range 33.3-61.6\%). No significant effects of year and stage on sex ratios (revealed by still shooting) were detected by multiple logistic regression $\left(\chi^{2}=2.84, d f 4, P=0.58\right)$.

Reproduction

The mean prevalence of pregnancy over 0-3 YPI was $47.4 \%$ and increased steadily and significantly with stage from $0 \%$ in juveniles to $64.6 \%$ in older sows $\left(\chi^{2}=16.45\right.$, df $3, P=0.001$ ) (Fig. 6a). Pregnancy rates among adult females declined significantly from $68.6 \%$ at baseline to $36.4 \%$ at 3 YPI $\left(\chi^{2}=10.99, d f\right.$ 3, $P=0.012$ ). Fecundity averaged 4.5 (standard deviation, SD, 1.74) embryos per pregnant sow and increased slightly with stage from 3.7 (SD, 2.29) embryos among young females to 4.5 (SD, 1.67) among older females. Most embryos occurred during winter (Fig. 6b).

Pig rooting and collateral effects

The fraction of strip transects affected by pig rooting decreased from 3.9 to $1.5 \%$ over $0-1$ YPI (a $61.5 \%$ reduction), respectively, to drop below $1 \%$ from late5 YPI on (Fig. 7a). Ground rooting fraction and standardized CPUE by still shooting were not significantly correlated (Spearman's $\rho=0.19, \mathrm{n}=12$, $P=0.56$ ). Fox abundance increased linearly (Adj. $\left.R^{2}=0.835, F=41.4,7 d f, P<0.001\right)$ up to 8 YPI (Fig. 7b).

Undesirable collateral effects comprised 15 events of capybaras molested or bitten by dogs, and one capybara shot; 23 dogs wounded, one dead and four missing; one hunter injured by a horse; consumption of wild boar bait by native wildlife; pollution with lead ammunition that missed the target, and a few cases of unauthorized logging to facilitate shooting.

\section{Discussion}

The management program substantially reduced the relative abundance of wild boar in 2 years at 5-7 \% month $^{-1}$ and then kept it at low levels across the next 8 years with $\mu$ indistinguishable from 0 , a target not stated among initial program goals. Pig rooting declined below target levels $(<1.3 \%)$ from 4 YPI on while yatay palm sapling mortality concomitantly 
Fig. 6 Stage-specific annual pregnancy (a) and fecundity rates by month (b) in El Palmar, 2006-2009. Stage 1, juveniles; 2, young adults; 3 , mature adults, and 4 , older adults
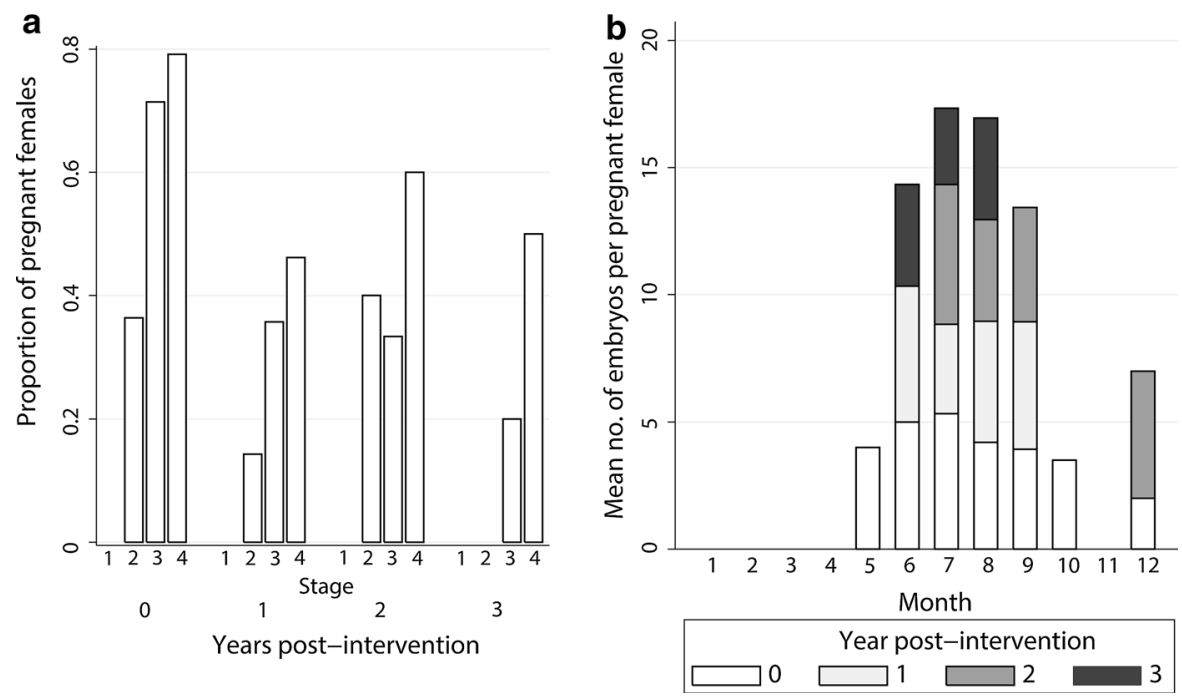

Fig. 7 Percentage of ground surface affected by pig rooting (a) and relative abundance of crab-eating and red foxes (b) in experimental strip transects in El Palmar, 2006-2014. Data over 3 and mid-4 YPI in a taken from Ballari (2014)
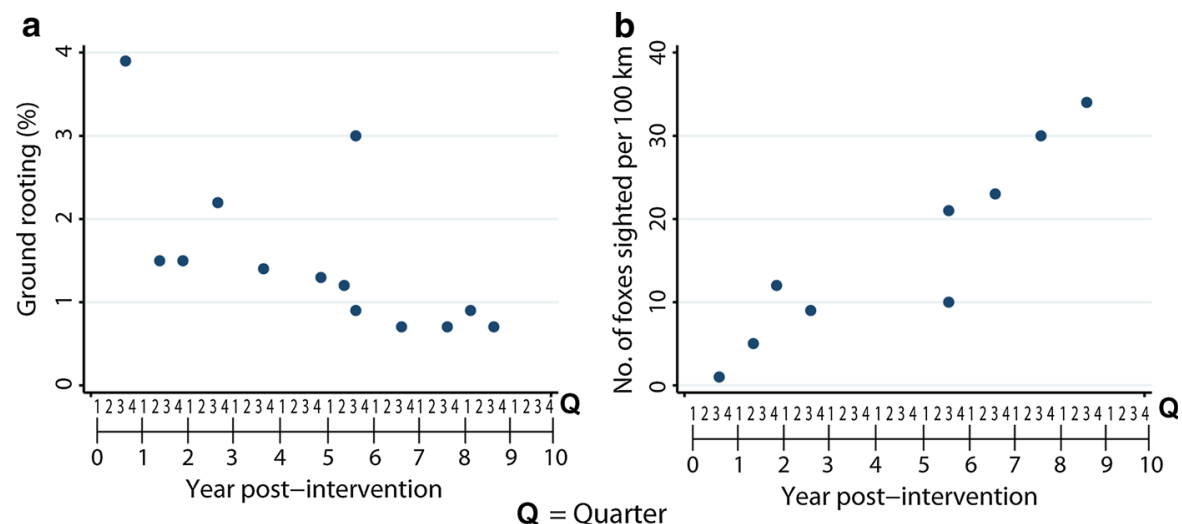

dropped from $32-81 \%$ between -4 and 1 YPI to $3 \%$ over 5-6 YPI (Lunazzi 2009; Ballari 2014). These consistent relationships support the validity of standardized CPUE indices for management purposes in closely-controlled hunting programs despite violation of the assumption of equal catchability among stages (Lancia et al. 1996), provided the bias may be assumed to remain roughly constant over time. The combined use of CPUE, body-length data and simple PVA models provided reliable tools for wild boar population trend analysis and management which have application to other sites and other harvested ungulate populations.

Background experience and views on controlled still shooting are heterogeneous. Shooting was considered to be time-consuming and moderately effective at eradicating feral pig populations in a Galapagos island (Coblentz and Baber 1987) whereas volunteer hunters eliminated or decimated wild boar in fenced areas from Hawaii (Burt et al. 2011). Others concluded that only shooting conducted by professional hunters (and poisoning) may quickly reduce wild boar population size, whereas recreational (sport) hunting usually exerted little effects because their operations are affected by conflicts of interest and poor planning (Massei et al. 2011; West et al. 2009; Hanson et al. 2009). The precise nature and implementation of controlled shooting (i.e., coverage, frequency, program duration and goal: eradication versus control; hunters' skills, adherence and supervision) differed substantially among reports and precludes a sweeping generalization.

Dog-hunting culled as many (absolute) or relatively more (CPUE) wild boar as still shooting over 0-1 YPI, provided a correlated index and less biased catches (as recorded for deer by Novak et al. 1991), and allowed to 
flexibly target park sections with fewer watchtowers and not accessible with vehicles. However, doghunting was almost discontinued once the abundance of wild boar declined because of the sizable amount of labor and expense implied by the maintenance of a dog pack, its more complex logistics and potentially adverse effects on native wildlife.

Our study documents a linear relation between catch and hunting effort over a broad range of conditions and estimates (except at large shooting effort), and thus supports a crucial, rarely tested assumption of CPUE-based assessments. In a related aspect, the CPUE of feral pigs shot from a helicopter or culled by dog-hunting bore a curvilinear relation to pig density (Hone 2007). A large departure from the linear assumption led to severe depletion of some fisheries and aggregative resource stocks (e.g., Hilborn and Walters 1992; Maunder et al. 2006). The equal-catchability assumption entails homogeneous catchability across park sections, seasons, years and hunters who may differ in ability and gear. Standardizing still-shooting effort (and catches) across years is a key issue we addressed by restricting sessions to a common, more effective time window. Use of crude hunting effort deflated the unadjusted CPUE indices over 0-1 YPI (when unusually long, overnight sessions were conducted) and virtually masked the declining population trend (not shown). Variations in the area coverage of still-shooting efforts among sessions or quarters were at times sizable and may explain some outliers. The slope coefficient of the linear catch-effort relationship estimates the work cost of culling a wild boar by still shooting at 20 huntingparty hours over a broad range of conditions.

The effects of little or no hunting activity over some extended periods were ambiguous: either the CPUE exceeded and remained above the long-term equilibrium (over 4-5 YPI) or surprisingly failed to resurge (after marginal effort over 6 YPI) despite the wellknown fast recovery of wild boar populations (e.g., Hone 2002; Morrison et al. 2007), the availability of suitable habitats with unrestricted access to water and food, absence of large predators, and lack of systematic boar control in neighboring farms. A yatay palm tree yields an average of $5 \mathrm{~kg}$ of fruit every summer, a predictable resource readily consumed by wild boar (Ballari et al. 2015), unlike the multiannual masting patterns of oak and beech trees in Europe (Jedrzejewska et al. 1997; Bieber and Ruf 2005) and of Araucaria araucana in Patagonia (Sanguinetti and Kitzberger 2010) which greatly affect wild boar diet, body weight and condition. Foxes, which may prey upon piglets elsewhere (Hone 2012), notoriously increased in abundance following a large outbreak of canine distemper in El Palmar over 0-1 YPI (Ferreyra et al. 2009). Whether foxes may have limited wild boar numbers remains unclear. Increased hunting-related disturbance over 7-9 YPI may have enhanced the avoidance behavior, movement and nocturnal activity of wild boar (Thurfjell et al. 2013; Ohashi et al. 2013) and eventually reduced $q$.

CPUE indices tended to display biannual peaks of abundance over $0-1$ YPI. These variations are likely related to the two birth pulses and the vacuum effect (Hone 2007): the local depletion of resident wild boar through culling combined with the disturbance created by shooting and dog-hunting, followed by subsequent in-migration and seasonal recruitment of large-sized individuals over spring-summer. Wild boar clearly qualify as a diffusive resource stock (Clark 1985).

Harvest composition was stage-biased (i.e., sizebiased). Body-length variations (closely related to wild boar age and body weight: Moretti 1995) captured the immediate impact of culling on the baseline stage distribution. The much lower fraction of older adults and juveniles from early 1 YPI on was an early sign of population decline whereas the relative increase of juveniles by early 5 YPI signaled incipient recovery. Although change-in-ratio methods have several weaknesses when used alone (Skalski et al. 2005), in conjunction with estimates of $\mu$ they support that both deviations from a stable structure were indicative of reduced and increased recruitment, respectively. Additionally, the low numbers of juveniles (including squeakers) across years and methods $(<33.7 \%)$ strongly support they were underrepresented relative to stable stage distributions which comprise 61-65\% of juveniles (Bieber and Ruf 2005). We infer that juveniles were less exposed to, sighted or prime targeted by the hunters, and thus suffered lower hunting mortality. This finding is very relevant because $\lambda$ is most affected by small changes in juvenile survival (elasticity) under good habitat conditions, in heavily hunted populations, and when $\lambda \leq 1$ (Bieber and Ruf 2005; Servanty et al. 2011; Hone 2012), as in El Palmar after 0-1 YPI.

Sex ratios computed from still-shooting harvests were consistently skewed toward males across stages 
and years, whereas expected sex ratios at birth and from dog-hunting were balanced. The sex differential was small and unlikely to result in depressed recruitment (Milner et al. 2007). A large male bias across wild boar stages was tentatively attributed to reduced female survival in California (Parkes et al. 2010) whereas increased female survival was recorded by a mark-recapture study in Georgia, US (Hanson et al. 2009). Wild boar typically live in matrilineal social groups led by a large sow followed by young females and juveniles (Kaminski et al. 2005) whereas males are solitary except during rutting. Therefore, males and sows were unlikely to be jointly exposed to still shooting, in which case males might be preferentially targeted because of their larger body size. In the absence of culling restrictions and no differential timing of exposure between sexes, males may have been culled more frequently because of their larger home range and because sows with offspring are more risk averse (Campbell and Long 2009; Saïd et al. 2012).

Fecundity patterns support a main birth pulse in winter and a putative secondary peak by late spring, which is compatible with wild boar generally having up to two annual litters or even breed year-round in some regions (e.g., Dzieciolowski et al. 1990; Saunders 1993). Pregnancy rates increased from nil among juveniles to roughly similar levels among mature and older sows, and were similar to those recorded in lowand high-quality habitats (40-50\%) elsewhere (Choquenot et al. 1996; Bieber and Ruf 2005). However, undetected early pregnancies and early removal of adult females along the reproductive season may have underestimated the actual rates in El Palmar. The marked decline in pregnancy rates over 0-3 YPI translated into reduced productivity of juvenilesanother impact of control actions.

Unlike its immediate predecessor, the multi-stakeholder program of wild boar succeeded in sustaining effective control operations over a decade. Part of the success may be attributed to the joint involvement of park personnel and local recreational hunters, continued institutional support, increased awareness of damages caused by wild boar, and perception of shared benefits through a food subsidy program. Getting regular access to wild boar and the persisting axis deer population were essential to sustain hunters' motivation and efforts as reflected in the creation of a “conservation hunters' club". Control activities did not affect recreational visitors to the park, and rarely caused adverse impacts on native wildlife; the apparent ones were minor and mainly related to doghunting. The outbreak of canine distemper affecting foxes was most likely related to the reiterated presence of free-ranging and poachers' dogs rather than to program's dogs which were kept under veterinary supervision. The program spurred renewed interest in the long-waited eradication of wild boar from Isla Victoria in Nahuel Huapí National Park (Simberloff et al. 2003) and control efforts in other national parks and conservation areas.

Our analyses are limited by lack of information on the rates of in- and out-migration of wild boar since the wired perimeter fences are no effective barriers; regression models implicitly assumed that both rates were negligible or cancelled out. Poachers' offtake was assumed negligible relative to regular culling whereas wounded specimens most likely were underreported and may represent crippling losses, the extent of which was sizable elsewhere (Servanty et al. 2010). In reference to specimens which lacked taxonomic identification, additional analysis including or excluding them did not affect the main inferences drawn from estimating the population growth rates of wild boar. Although rooting and yatay sapling mortality supported the validity of CPUE indices, additional estimates of wild boar abundance would be informative. CPUE indices for still shooting and dog-hunting were significantly correlated but they are not exactly based on the same currency; both methods competed for wild boar over 0-1 YPI and may have mutually interfered as they depleted the stock. Whether the concurrent hunting of axis deer modified wild boar $q$ merits further research. If catchability decreases with large shooting effort and associated disturbances (Fig. 3a), the actual abundance of wild boar may be substantially underestimated at large effort levels. A noteworthy strength of the management program was to keep records of hunting effort, catch and other attributes for interim assessment and decision making. A cost-effectiveness analysis of the program is relevant.

Analysis of program outputs may help to refine the effectiveness and efficiency of ongoing and future management practices. The distribution of hunting effort was heterogeneous in time and space, and was mainly determined by logistic reasons and hunters' decisions, not wild boar population dynamics. How to 
allocate the intensity of hunting effort optimally over space and time is an important question (Bieber and Ruf 2005; Gamelon et al. 2012). Unlike the situation in Europe, New Zealand and Australia where major increases in effort and harvest rates are required to control wild boar (Dzieciolowski et al. 1990; Caley 1993; Bieber and Ruf 2005; Hone 2007), their abundance in El Palmar may be lowered further by tailoring hunting efforts to the local setting rather than by merely increasing their intensity. Candidate measures include identifying and targeting park sections with high-quality wild boar habitat and lower hunting coverage at appropriate times, and increasing hunting pressure on juvenile and adult females prior to or during the reproductive season (winter). Pending relevant information on local survival rates for use in age- or size-structured models (Servanty et al. 2011; Gamelon et al. 2012), the empirical evidence collected between mid-2 and 4 YPI at El Palmar roughly suggests that 750 hunting party-hours per quarter (including 150 parties using current procedures) can keep wild boar numbers at bay. The space-time distribution of hunting effort may be critical to prevent excess disturbance and pig evasion. Because wild boar are abundant across the region, local farmers should be integrated into the management program and undertake coordinated control (Choquenot et al. 1996); no progress has been made in this direction. In this context, both the sustainability and cost-effectiveness of management operations are crucial to maintain the current low-impact status of wild boar in El Palmar. Relaxing the intensity of controlled hunting efforts may lead to the fast recovery of wild boar populations within a few years.

Acknowledgments The management program of exotic ungulates at El Palmar National Park is a collective undertaking nurtured by the untiring commitment of APN personnel to the conservation mission: A. Delaloye, E. Jones, J. Yone, G. Brossard, J. Ballay, A. Luggren, J. Zermathen, R. Antunez, E. Alzogaray, G. Gaillard, L. Rey, E. Francisconi, J. Colodro, L. Loyza, J. Baliño, M. Panziera, E. Munich, E. Bouvet, N. Abdala, V. Jones, L. Barrios Caro, N. Zermathen, M. Cardoso, L. Rivas, N. Ballay, A. Faure, E. Irazoqui, volunteers and members of the Hunting Club for Conservation "Tierra de Palmares". Park map was prepared by Julio Baliño. Weather data were provided by Servicio Meteorológico Nacional. REG thanks the advice provided by Jean-Pierre Dujardin, Sol Gaspe, Lucía Rodríguez Planes and María del Pilar Fernández. The participation of REG was supported by University of Buenos Aires and Fundación Bunge and Born. The funders had no role in study design, data collection and analysis, decision to publish and preparation of the manuscript.

\section{Compliance with ethical standards}

Conflict of interest The authors declare no conflict of interest.

\section{References}

Ballari SA (2014) El jabalí (Sus scrofa) en el Parque Nacional El Palmar, Entre Ríos: uso de hábitats, dieta, impactos y manejo. Dissertation, Universidad Nacional de Córdoba, Argentina

Ballari SA, Cuevas MF, Ojeda RA, Navarro JL (2015) Diet of wild boar (Sus scrofa) in a protected area of Argentina: the importance of baiting. Mamm Res 60:81-87

Barrios-García MN, Ballari SA (2012) Impact of wild boar (Sus scrofa) in its introduced and native range: a review. Biol Invasions 14:2283-2300

Batista WB, Rolhauser AG, Biganzoli F, Burkart SE, Goveto L, Maranta A, Pignataro AG, Morandeira NS, Rabadán M (2014) Savanna plant community types at El Palmar National Park (Argentina). Darwiniana (new series) 2:5-38

Bieber C, Ruf T (2005) Population dynamics in wild boar Sus scrofa: ecology, elasticity of growth rate and implications for the management of pulsed resource consumers. J Appl Ecol 42:1203-1213

Burt MD, Miller C, Souza D (2011) The use of volunteer hunting as a control method for feral pig populations on O'ahu, Hawai'i. In: Veitch CR, Clout MN, Towns DR (eds) Island invasives: eradication and management. IUCN, Gland, pp 402-406

Caley P (1993) Population dynamics of feral pigs (Sus scrofa) in a tropical riverine habitat complex. Wildl Res 20:625-636

Campbell TA, Long DB (2009) Feral swine damage y damage management in forested ecosystems. For Ecol Manag 257:2319-2326

Choquenot D, McIlroy J, Korn T (1996) Managing vertebrate pests: feral pigs. Bureau of Resource Sciences, Australian Government Publishing Service, Canberra

Clark CW (1985) Bioeconomic modelling and fisheries management. Wiley, New York

Coblentz BE, Baber DW (1987) Biology and control of feral pigs on Isla Santiago, Galapagos, Ecuador. J Appl Ecol 24:403-418

Cohen M, Costantino SN, Calcagno MA, Blanco GA, Pozio E, Venturiello SM (2010) Trichinella infection in wild boars (Sus scrofa) from a protected area of Argentina and its relationship with the presence of humans. Vet Parasitol 169:362-366

Crespo JA (1982) Introducción a la ecología de los mamíferos del Parque Nacional El Palmar, Entre Ríos. Anales de Parques Nacionales (Argentina) 15:1-34

Cruz F, Donlan CJ, Campbell K, Carrion V (2005) Conservation action in the Galápagos: feral pig (Sus scrofa) eradication from Santiago Island. Biol Conserv 12:473-478

Dzieciolowski RM, Clarke CMH, Fredric BJ (1990) Growth of feral pigs in New Zealand. Acta Theriol 35:77-88 
Ferreyra H, Calderón MG, Marticorena D, Marull C, Barrios Caro L (2009) Canine distemper infection in crab-eating fox (Cerdocyon thous) from Argentina. J Wildl Dis 45:1158-1162

Gamelon M, Gaillard JM, Servanty S, Gimenez O, Toigo C, Baubet E, Klein F, Lebreton JD (2012) Making use of harvest information to examine alternative management scenarios: a body weight structured model for wild boar. J Appl Ecol 49:833-841

Gaspe MS, Gurevitz JM, Gürtler RE, Dujardin JP (2013) Origins of house reinfestation with Triatoma infestans following insecticide spraying in rural Argentine Chaco using wing geometric morphometry. Inf Gen Evol 17:93-100

Goveto L (1999) Manejo adaptativo de las poblaciones de jabalíes en las áreas protegidas. Administración de Parques Nacionales, Buenos Aires, pp 1-46

Hanson LB, Mitchell MS, Grand JB, Jolley DB, Sparklin BD, Ditchkoff SS (2009) Effect of experimental manipulation on survival and recruitment of feral pigs. Wildl Res 36:185-191

Hilborn R, Walters CJ (1992) Quantitative fisheries stock assessment. Choice, dynamics and uncertainty. Chapman and Hall, New York

Hone J (2002) Feral pigs in Namadgi National Park, Australia: dynamics, impacts and management. Biol Conserv 105:231-242

Hone J (2007) Wildlife damage control. CSIRO Publishing, Collingwood

Hone J (2012) Applied population and community ecology: the case of feral pigs in Australia. Wiley-Blackwell, West Sussex

Jedrzejewska B, Jedrzejewski W, Bunevich AN, Milkowski L, Krasinski A (1997) Factors shaping population densities and increased rates of ungulates in Bialowieza Primeval Forest (Poland and Belarus) in the 19th and 20th centuries. Acta Theriol 42:399-451

Kaminski G, Brandt S, Baubet E, Baudoin C (2005) Life-history patterns in female wild boars (Sus scrofa): motherdaughter postweaning associations. Can J Zool 83:474-480

Lancia RA, Bishir JW, Conner MC, Rosenberry CS (1996) Use of catch-effort to estimate population size. Wildl Soc Bull 24:731-737

Lowe S, Browne M, Boudjelas S, De Poorter M (2004) 100 of the world's worst invasive alien species: a selection from the global invasive species database. Invasive Species Specialist Group, Auckland

Lunazzi MM (2009) Demografía de la palmera Butia yatay en el Parque Nacional El Palmar: distribución y estructura de las poblaciones en las escalas de paisaje y de stand. MSc dissertation. Facultad de Agronomía, Universidad de Buenos Aires

Massei G, Roy S, Bunting R (2011) Too many hogs? A review of methods to mitigate impact by wild boar and feral hogs. Human-Wildl Int 5:79-99

Massei G, Kindberg J, Licoppe A et al (2015) Wild boar populations up, numbers of hunters down? A review of trends and implications for Europe. Pest Manag Sci 71:492-500

Maunder MN, Sibert JR, Fonteneau A, Hampton J, Kleiber P, Harley SJ (2006) Interpreting catch per unit effort data to assess the status of individual stocks and communities. ICES J Mar Sci 63:1373-1385
Merino ML, Carpinetti BN, Abba AM (2009) Invasive mammals in the national park system of Argentina. Nat Areas J 29:42-49

Milner JM, Nilsen EB, Andreassen HP (2007) Demographic side effects of selective hunting in ungulates and carnivores. Conserv Biol 21:36-47

Moretti M (1995) Biometric data and growth rates of a mountain population of wild boar (Sus scrofa L.), Ticino, Switzerland. J Mt Ecol (Ibex) 3:56-59

Morris WF, Doak DF (2002) Quantitative conservation biology: theory and practice of population viability analysis. Sinauer, Sunderland

Morrison SA, Macdonald N, Walker K, Lozier L, Shaw MR (2007) Facing the dilemma at eradication's end: uncertainty of absence and the Lazarus effect. Front Ecol Environ 5:271-276

Novak JM, Scribner KT, Dupont WD, Smith MH (1991) Catcheffort estimation of white-tailed deer population size. J Wildl Manag 55:31-38

Novillo A, Ojeda RA (2008) The exotic mammals of Argentina. Biol Invasions 10:1333-1344

Ohashi H, Saito M, Horie R et al (2013) Differences in the activity pattern of the wild boar Sus scrofa related to human disturbance. Eur J Wildl Res 59:167-177

Oli MK, Dobson FS (2003) The relative importance of lifehistory variables to population growth rate in mammals: Cole's prediction revisited. Am Nat 161:422-440

Parkes JP, Ramsey DSL, Macdonald N, Walker K, McKnight S, Cohen BS, Morrison SA (2010) Rapid eradication of feral pigs (Sus scrofa) from Santa Cruz Island, California. Biol Conserv 143:634-641

Pérez Carusi LC, Beade MS, Miñarro F, Vila AR, GiménezDixon M, Bilenca DN (2009) Relaciones espaciales y numéricas entre venados de las pampas (Ozotoceros bezoarticus celer) y chanchos cimarrones (Sus scrofa) en el Refugio de Vida Silvestre Bahía Samborombón, Argentina. Ecol Austral 19:63-71

Pignataro AG (2010) Controles de la regeneración de la palmera Butia yatay en el Parque Nacional El Palmar. MSc dissertation. Facultad de Agronomía, Universidad de Buenos Aires

Saïd S, Tolon V, Brandt S, Baubet E (2012) Sex effect on habitat selection in response to hunting disturbance: the study of wild boar. Eur J Wildl Res 58:107-115

Sanguinetti J, Kitzberger T (2010) Factors controlling seed predation by rodents and non-native Sus scrofa in Araucaria araucana forests: potential effects on seedling establishment. Biol Invasions 12:689-706

Saunders G (1993) The demography of feral pigs (Sus scrofa) in Kosciusko National Park, New South Wales. Wildl Res 20:559-569

Servanty S, Choquet R, Baubet E, Brandt S, Gaillard JM, Schaub M, Toïgo C, Lebreton JD, Buoro M, Gimenez O (2010) Assessing whether mortality is additive using marked animals: a Bayesian state-space modeling approach. Ecology 91:916-923

Servanty S, Gaillard JM, Ronchi F, Focardi S, Baubet E, Gimenez O (2011) Influence of harvesting pressure on demographic tactics: implications for wildlife management. J Appl Ecol 48:835-843 
Simberloff D, Relva MA, Nuñez M (2003) Introduced species and management of a Nothofagus/Austrocedrus forest. Environ Manag 31:263-275

Skalski JR, Ryding KE, Millspaugh JJ (2005) Wildlife demography. Analysis of sex, age, and count data. Elsevier Academic Press, Boston

StataCorp (2011) Stata statistical software: release 12.0. Stata Corporation, College Station
Thurfjell H, Spong G, Ericsson G (2013) Effects of hunting on wild boar Sus scrofa behavior. Wildl Biol 19:87-93

Vetter SG, Ruf T, Bieber C, Arnold W (2015) What is a mild winter? Regional differences in within-species responses to climate change. PLoS One 10:e0132178

West BC, Cooper AL, Armstrong JB (2009) Managing wild pigs: a technical guide. Human-Wildl Int Monogr 1:1-55 